\title{
Managing Exacerbations in Thunderstorm Asthma: Current Insights
}

\author{
Josh Chatelier $\mathbb{D}^{1,2}$ \\ Samantha Chan ${ }^{1-3}$ \\ Ju Ann Tan ${ }^{1,2}$ \\ Alastair G Stewart ${ }^{4,5}$ \\ Jo Anne Douglass ${ }^{1,2}$ \\ 'Department of Clinical Immunology and \\ Allergy, Royal Melbourne Hospital, \\ Parkville, Victoria, Australia; \\ ${ }^{2}$ Department of Medicine, University of \\ Melbourne, Melbourne, Victoria, \\ Australia; ${ }^{3}$ mmunology Division, The \\ Walter \& Eliza Hall Institute of Medical \\ Research, Parkville, Victoria, Australia; \\ ${ }^{4}$ Department of Biochemistry and \\ Pharmacology, School of Biomedical \\ Sciences, University of Melbourne, \\ Melbourne, Victoria, Australia; ${ }^{5}$ ARC \\ Centre for Personalised Therapeutics \\ Technologies, University of Melbourne, \\ Melbourne, Victoria, Australia
}

\begin{abstract}
Epidemic thunderstorm asthma (ETSA) occurs following a thunderstorm due to the interaction of environmental and immunologic factors. Whilst first reported in the $1980 \mathrm{~s}$, the world's largest event in Melbourne, Australia, on November 21, 2016 has led to a wealth of clinical literature seeking to identify its mechanisms, susceptibility risk factors, and management approaches. Thunderstorm asthma (TA) typically presents during an aeroallergen season in individuals sensitized to perennial rye grass pollen (RGP) in Australia, or fungus in the United Kingdom, in combination with meteorological factors such as thunderstorms and lightning activity. It is now well recognized that large pollen grains, which usually lodge in the upper airway causing seasonal allergic rhinitis (SAR), are ruptured during these events, leading to sub-pollen particles respirable to the lower respiratory tract causing acute asthma. The identified risk factors of aeroallergen sensitization, specifically to RGP in Australians with a history of SAR, and individuals born in Australia of South-East Asian descent as a risk factor for TA has been key in selecting appropriate patients for preventative management. Moreover, severity-determining risk factors for ETSA-related asthma admission or mortality, including pre-existing asthma or prior hospitalization, poor inhaled corticosteroid adherence, and outdoor location at the time of the storm are important in identifying those who may require more aggressive treatment approaches. Basic treatments include optimizing asthma control and adherence to inhaled corticosteroid therapy, treatment of SAR, and education regarding TA to increase recognition of at-risk days. Precision treatment approaches may be more beneficial in select individuals, including the use of allergen immunotherapy and even biologic treatment to mitigate asthma severity. Finally, we discuss the importance of environmental health literacy in the context of concerns surrounding the increased frequency of ETSA due to climate change and its implications for the frequency and severity of future events.
\end{abstract}

Keywords: epidemic thunderstorm asthma, thunderstorm asthma, seasonal allergic rhinitis

\section{Introduction}

Epidemic thunderstorm asthma (ETSA) events are recognized as health disasters characterized by multiple presentations of acute asthma following a thunderstorm. Historically, ETSA occurs unexpectedly, causing an overwhelming burden on health care services. The combination of environmental and individual factors are key determinants of the occurrence of ETSA. The world's largest ETSA event occurred on November 21, 2016, in Melbourne, Australia, with a 672\% increase in respiratory-related emergency department (ED) presentations (3,365 more cases than expected), which led to 10 tragic deaths. ${ }^{1-5}$ This event was challenging to emergency and health care services due to the sudden and unforeseen increase in
Correspondence: Josh Chatelier Department of Clinical Immunology and Allergy, Royal Melbourne Hospital, Parkville, Victoria, Australia

Tel +6I 393427191

$\mathrm{Fax}+61393493199$

Email josh.chatelier2@mh.org.au 
the numbers of acutely unwell patients. This tragic event has led to increased recognition of ETSA, prompting consideration of strategies for management, as well as implementation of health campaigns and forecasting alert systems.

The pathogenesis of thunderstorm asthma (TA) has been shown to depend on the combination of aeroallergen sensitization, particularly with ryegrass pollen (RGP), seasonal allergic rhinitis (SAR), including in those without a prior diagnosis of asthma, and follows within hours of a recent thunderstorm. ${ }^{6,7}$ The severity of TA causing presentation to hospital has been correlated with a history of pre-existing or prior hospital admission with asthma, South Asian ethnicity, and the presence of elevated levels of specific immunoglobulin E (sIgE) to RGP. ${ }^{1,8}$ The wind-pollinated pasture grass, perennial ryegrass (Lolium perenne) with major allergen Lol p 5, is prevalent in south-eastern Australia in the spring season. Intact ryegrass pollen grains are $\geq 30 \mu \mathrm{m}$ in diameter, preferentially lodging in the upper respiratory tract to cause naso-ocular symptoms consistent with allergic rhinitis (AR). ${ }^{8}$ In TA, these grains are ruptured by osmotic shock when exposed to high levels of moisture or by lightning activity itself, releasing thousands of sub-pollen particles (SPP) of size $\leq 2.5 \mu \mathrm{m}$ respirable to the level of the lower respiratory tract, causing bronchoconstriction and the clinical presentation of TA. ${ }^{9,10}$ Other important factors associated with TA severity include high aeroallergen levels, and meteorological factors such as the influence of annual rainfall on grassland biomass and pollen production, rapid temperature changes, high humidity, thunderstorm wind outflows, convergence line weather events, geographical location, and lightning activity itself. ${ }^{4,9,11,12}$ The understanding of TA has required a wide range of interdisciplinary research across multiple fields in health, botany, and atmospheric sciences.

\section{Overview of Historical Episodes}

The first published reports of epidemics of acute respiratory distress associated with exceptional weather conditions was published from Birmingham, UK in 1983 with approximately 106 attendances of patients with Didymella exitialis and Sporobolomyces allergy. ${ }^{13}$ Prior to this, epidemic asthma events were usually documented in conjunction with elevated levels of air pollutants, such as smog ${ }^{14-16}$ and castor-bean dust. ${ }^{17}$ However, there were earlier studies noting associations with sudden temperature changes and high barometric pressure. $^{18}$ In total, there have now been 27 documented ETSA episodes occurring across the globe, with the majority affecting Australia (10), the UK (7), and also Europe, North
America, the Middle East, and China (Table 1). It must be noted that there have been multiple worldwide locations reporting increased asthma presentations coinciding with thunderstorms that have not been formally documented as ETSA, ${ }^{19,20}$ suggesting that the occurrence is more common than currently appreciated. Furthermore, convergence line weather events have been associated with a significant proportion of increased asthma presentations which may not always be thunderstorm related, including in Australia and Iran. ${ }^{21,22}$ The largest ETSA event prior to 2016 was in the UK in 1994, attributed to grass pollen (GP) allergen, with 640 hospital attendances, five intensive care unit (ICU) admissions, and the first ETSA-related death. ${ }^{6}$ To date, there have been cumulative reports of over 7,000 hospital presentations with 18 reported deaths due to ETSA. In Australia, the frequency of ETSA is approximately two per decade. The absence of a predictable pattern is a clear concern for deploying effective population health measures. Despite ETSA events being uncommon, asthma exacerbations following thunderstorms are likely under-reported. Furthermore, from an environmental perspective, the effects of climate change carry the potential to increase aeroallergen concentration, and increase the frequency of extreme weather events such as thunderstorms, posing a great risk for the future health and wellbeing of the large at-risk population. ${ }^{23}$

\section{Management Overview}

Management of ETSA can be divided into identification of risk factors to enable targeting of preventive therapies to those at greatest predicted risk, individual preventative management, and larger systems-based approaches such as forecast alert systems and environmental health literacy. The approach to medical management of TA progresses from allergen avoidance to desensitization, an emphasis on drug treatment of asthma with on demand inhaled corticosteroid (ICS)/longacting beta agonist (LABA) now indicated in steps 1 and 2 of the Global Initiative For Asthma (GINA) guidelines for mild asthma, ${ }^{24}$ to novel treatment options, such as prophylactic biologic therapies. The emerging options include allergenspecific immunotherapy to induce immunological tolerance in sensitized individuals, as well as considerations for precision therapy to prevent ETSA with monoclonal antibody agents targeting components of the T-helper 2 (TH-2) specific cascade such as IgE (omalizumab), interleukin (IL)-5 (benralizumab and mepolizumab), and IL-4/IL-13 (dupilumab). The general emergence of environmental health literacy (EHL) facilitates public awareness, empowering communities to reduce exposures to potentially harmful environmental conditions, and has 
Table I Summary of Reported Episodes of ETSA to Date

\begin{tabular}{|c|c|c|c|c|c|c|}
\hline Location & Date & Season & $\begin{array}{l}\text { Hospital } \\
\text { Presentations }\end{array}$ & Death & Allergen Trigger(s) & Reference \\
\hline UK, Birmingham & 1983, Jul & Summer & 106 & 0 & Didymella exitialis, Sporobolomyces & {$[12]$} \\
\hline UK, Nottingham & 1984, Jun & Summer & 19 & 0 & Didymella exitialis, I GP & [91] \\
\hline Australia, Melbourne & 1984, Nov & Spring & 85 & 0 & Not specified & [92] \\
\hline Australia, Melbourne & 1987, Nov & Spring & 154 & 1 & Grass pollen & [32] \\
\hline UK, Leicester & I989, Jul & Summer & 32 & 0 & Didymella ascospores & [93] \\
\hline Australia, Melbourne & 1989, Nov & Spring & 277 & 0 & Grass pollen & [32] \\
\hline Australia, Tamworth & 1990, Nov & Spring & 110 & 0 & Grass pollen & [94] \\
\hline UK, London & 1994, Jun & Summer & 640 & 1 & Grass pollen & [20] \\
\hline Australia, Wagga & 1997, Oct & Spring & 215 & 0 & Grass pollen & [25] \\
\hline Australia, Newcastle & 1998, Oct & Spring & 6 & 0 & Grass pollen & [45] \\
\hline Canada, Calgary & 2000, Jul & Summer & 157 & 0 & Amaranthaceae pollen, Myxomycetes Fungi & [42] \\
\hline UK, Cambridge & 2002, Jul & Summer & 57 & 1 & Alternaria spores & [4I] \\
\hline Saudi Arabia, Al-Khobar & 2002, Nov & Autumn & NS & NS & NS & [95] \\
\hline Australia, Melbourne & 2003, Nov & Spring & 70 & 0 & Grass pollen & [34] \\
\hline Italy, Naples & 2004, Jun & Summer & 7 & 0 & Parietaria pollen & [43] \\
\hline UK, South-East England & 2005, Jun & Summer & NS & NS & NS & [96] \\
\hline Italy, Puglia & 2010, May & Spring & 20 & 0 & Olive tree pollen & [44] \\
\hline Australia, Melbourne & 2010, Nov & Spring & 36 & 0 & Grass pollen & [28] \\
\hline Australia, Melbourne & 2011, Nov & Spring & 30 & 0 & Grass pollen & [28] \\
\hline UK, London & 20I3, Jul & Summer & 40 & 0 & NS & [97] \\
\hline Iran, Ahvaz & 2013, Nov & Autumn & 443 & 0 & Conocarpus erectus & {$[8,98,101]$} \\
\hline Australia, Canberra & 2014, Oct & Spring & 15 & 0 & Grass pollen & [99] \\
\hline Israel & 2015, Oct & Winter & NS & NS & NS & {$[102]$} \\
\hline Iran, Ahvaz & 2015, Oct & Autumn & NS & 0 & NS & [103] \\
\hline Australia, Melbourne & 2016, Nov & Spring & 3,365 & 10 & Grass pollen & [4] \\
\hline Middle East, Kuwait & 2016, Dec & Winter & 844 & 5 & NS & {$[100]$} \\
\hline Hamilton, New Zealand & 2017, Dec & Summer & 38 & 0 & NS & [105] \\
\hline China, Yulin & 2018, Sep & Autumn & 392 & 0 & Mugwort pollen & [104] \\
\hline
\end{tabular}

Note: Adapted from ${ }^{6}$.

Abbreviations: UK, United Kingdom; NS, not specified.

specific application in the population health management approach to ETSA. Public forecast notification systems are now established to operate in the spring season in Victoria, Australia, combining data on grass pollen levels, thunderstorm predictions, and wind speed to predict low, moderate, and highrisk days. This enables health and emergency services to be suitably prepared, and to alert the general public of preparedness for at risk days. This forecasting depends on EHL to reduce the health impacts of an ETSA event. Here, we discuss the current available options and potential new insights into managing ETSA.

\section{Mechanisms and Risk Factors Meteorological Factors}

Our current understanding of ETSA is from the combined result of complex environmental and individual factors. The precise mechanism of ETSA is not fully understood, however the key factors that have been identified include exposure to respirable particles of aeroallergens in sensitized individuals which are concentrated in thunderstorm downdrafts. ${ }^{6}$ Factors that may influence the scale of the event itself are likely to include the exposure of highdensity urban populations, the time of day, with the influence on outdoor air exposure, priming of sensitized individuals in the days preceding the event, and the prevalence of unmedicated patients. ${ }^{4}$ A summary of previously described risk factors is depicted in Table 2. Although there is incomplete data on some of the prior ETSA events, there is a consistent association with higher levels of aeroallergens, particularly grass pollen (GP) and fungi, in the days before significant ETSA events. ${ }^{25}$ These findings are clearly limited by the air sample collection methods, including the proximity of monitoring to the affected locations. Another common association is that of spring and summer seasons, which typically 
Table 2 Summary of Risk Factors for Thunderstorm Asthma

\begin{tabular}{|c|c|c|}
\hline Category & Evidence & Reference \\
\hline \multicolumn{3}{|l|}{ Environmental } \\
\hline $\begin{array}{l}\text { Aeroallergen } \\
\text { concentration }\end{array}$ & Extremely high levels of RGP recorded in preceding days before the Melbourne 2016 event & [4] \\
\hline Rainfall, humidity & Rainfall and humidity can lead to rupturing of pollen grains by osmotic shock & {$[10]$} \\
\hline Lightning activity & Lightning can rupture pollen grains & [9] \\
\hline $\begin{array}{l}\text { Sudden temperature } \\
\text { changes }\end{array}$ & Observational data & [8] \\
\hline Air pollution & Possible contributing factor, more research warranted & [9] \\
\hline Climate change & Potential to increase aeroallergen biomass and severe weather events & {$[31]$} \\
\hline \multicolumn{3}{|l|}{ Aeroallergens } \\
\hline Rye grass pollen & Evidence of high skin prick or slgE levels in affected individuals & {$[7,46]$} \\
\hline Fungal spores & Fungal sensitization in UK patients & {$[42]$} \\
\hline Other & Specific pollen associated with geographic region (eg, Olive tree) & [5] \\
\hline \multicolumn{3}{|l|}{ Immunological } \\
\hline $\begin{array}{l}\text { Aeroallergen } \\
\text { immunotherapy }\end{array}$ & $\begin{array}{l}\text { RCT of pre-seasonal grass SLIT in } 34 \text { subjects with SAR found that SLIT was protective for the } 2016 \\
\text { Melbourne event: no SLIT patients reported an asthma exacerbation on that day, compared with } 41 \% \text { (7// } 7) \\
\text { on pharmacotherapy alone }\end{array}$ & {$[5]$} \\
\hline Genetic & $\begin{array}{l}\text { Increasing severity if born in Australia of Asian ethnicity } \\
\text { Ongoing studies required }\end{array}$ & [6] \\
\hline \multicolumn{3}{|l|}{ Individual } \\
\hline Behavioral & Outdoor air exposure & {$[3,4]$} \\
\hline Ethnicity & $\begin{array}{l}39 \% \text { of ED presentations had Indian or Asian ethnicity } \\
\text { Asians who are born in Australia have an increased risk of hospital admission (odds ratio=5.4) }\end{array}$ & {$[1]$} \\
\hline Asthma & $\begin{array}{l}\text { Current asthma increases risk of hospital admission (odds ratio }=1.9 \text { ) } \\
\text { Recent asthma admission increases risk of hospital admission (odds ratio=3.2) }\end{array}$ & {$[1]$} \\
\hline Allergic rhinitis & $87 \%$ of individuals presenting to ED have SAR & {$[1]$} \\
\hline
\end{tabular}

Abbreviations: RGP, rye grass pollen; slgE, serum specific immunoglobulin E; UK, United Kingdom; RCT, randomized control trial; SLIT, sublingual immunotherapy; ED, emergency department; SAR, seasonal allergic rhinitis.

may have higher concentrations of aeroallergens; all previous ETSA events in Australia have occurred in spring. ${ }^{3}$ Increased rainfall prior to the spring-time period has been shown to increase grassland biomass and subsequent grass pollen formation. ${ }^{26}$ For previous Australian ETSA events where clinical data was recorded, nearly all patients had SAR with confirmed RGP sensitization. ${ }^{6}$

Studies have noted the ability of osmotic shock to rupture RGP grains to release ultra-fine respirable particles which can lodge in the small airways. ${ }^{10}$ This mechanism may offer some explanation for the report that describes as few as $10 \%$ of affected patients having previously known asthma. ${ }^{27}$ The role of high humidity and pollen rupture due to osmotic shock has been frequently quoted in previous studies. However, recent insights into other mechanisms have suggested that lightning may underpin SPP generation. ${ }^{9}$ The SPPs are concentrated by emergent weather events and then transported to ground level by the thunderstorm outflow tract which may be facilitated by outflows and cold down drafts. ${ }^{28}$ The role of air pollution as an additional co-factor for TA remains uncertain, as higher levels of $\mathrm{PM}_{10}$ (associated with acute asthma) ${ }^{29}$ 
were noted prior to the 2016 Melbourne ETSA event, and also described in other studies. ${ }^{2,30}$

Climate change may bring an increased frequency of precedent conditions for ETSA, not only for the Australian population, but also for other major cities that may begin to encounter similar environmental conditions. Increasing atmospheric greenhouse gases have dramatically increased since the Industrial Era commencing in the 1750s, with rapid changes recorded in the last 50 years. The increasing air temperatures and carbon dioxide concentration are associated with increased pollen production and lengthening of pollen seasons that may be expected to increase levels of population sensitization. ${ }^{26}$ Alongside this, the projected increase in extreme weather events, including flooding and tropical cyclones, may increase mold growth in homes, and thunderstorm frequency itself might increase the risk of large ETSA events. $^{31,32}$

\section{Aeroallergens and Aerobiology}

In studies of ETSA from South-Eastern Australia, the dominant associated allergen is RGP, with subsequent confirmed sensitization in affected individuals suggesting this is likely a key trigger. ${ }^{1-6,8}$ Assessment of causative aeroallergens has been subject to ascertainment bias, with investigations being limited to specific pollen or spore types. Moreover, only half of ETSA studies have aeroallergen exposure data. ${ }^{6}$ Despite these limitations, the collective evidence for a role for RGP is compelling for Australian events, with elevated levels documented prior to ETSA events. ${ }^{33}$ By contrast, the UK events have occurred in summer, with exposure to high levels of fungal spores. ${ }^{6}$

Grass pollens are a major source of allergens during spring season in Australia, and are thought to be the major trigger of Australian ETSA events. ${ }^{3,6}$ It is therefore not surprising that sensitization to RGP in particular was a dominant characteristic of patients affected during ETSA epidemics in Melbourne. ${ }^{33,34}$ RGP as a potential allergenic trigger was first alluded to in a case-controlled study following the epidemic events in Melbourne in 1987 and 1989, where 12 ETSA affected patients reported a greater likelihood of RGP allergy in comparison with asthma patients unaffected by ETSA. ${ }^{34}$ A follow-up study on patients who presented to the ED with ETSA during the 2016 Melbourne epidemic found that $100 \%$ were sensitized to RGP, with a mean $\operatorname{sigE}$ of $55 \pm 34 \mathrm{kUA} / \mathrm{L}$ (normal range $1-100 \mathrm{kUA} / \mathrm{L}) .^{33}$ The rate of RGP sensitization was significantly higher in ETSA-affected patients compared to severe asthma patients unaffected during an ETSA event. ${ }^{35}$ Similar observations were made in all the previously reported ETSA episodes in Melbourne, ${ }^{4,30,34,36}$ and also Wagga Wagga in New South Wales. ${ }^{27}$

Lol p 1 (35 kDA glycoprotein) and Lol p 5 (28-32 $\mathrm{kDA}$ glycoprotein) are identified as the major allergenic proteins in RGP as they account for $>90 \%$ of $\operatorname{IgE}$ mediated reactions in sensitized individuals. ${ }^{37-39}$ Lol p 5 is mainly found in the starch granules of RGP, whereas Lol p 1 is present in the cytoplasm of mature pollen grains and subsequently secreted on its surface. ${ }^{40}$ Symptoms of SAR are triggered when intact pollen grains are lodged in the upper airways and patients are exposed to Lol $\mathrm{p} 1$. On the other hand, a key mechanistic feature during thunderstorms is rainfall-related pollen rupture leading to the release of Lol p 5 containing starch granules as described in a seminal paper by Suphioglu et al. ${ }^{41}$ Extremely high levels of these starch granules, up to 50 -fold, can be detected in the Melbourne atmosphere following rainfall and bronchial provocation testing with starch granules on asthma patients has been shown to elicit symptoms of reversible airway constriction. ${ }^{41}$ These findings were further supported by a recent report on ETSA patients who presented to the $\mathrm{ED}$, in which mean blood sIgE to Lol p 5 was higher compared to non-ETSA asthma controls. ${ }^{8}$ Further receiver-operating characteristic (ROC) analysis suggested that measuring Lol p 5 sIgE was useful in distinguishing TA patients from other asthma patients, whereas Lol p $1 \mathrm{sIgE}$ had no diagnostic utility. ${ }^{8}$ Although the role of Lol p 5 as a biomarker in ETSA risk assessment is worth further confirmation at present, assays for Lol p $5 \operatorname{sIgE}$ are not commercially available in Australia, rendering its measurement currently a research tool.

Due to geographical differences, the responsible aeroallergen in TA might vary in other global communities, limiting the validity of extrapolating Australian data. It would be of great relevance to note the patterns of predominant aeroallergen sensitization as a risk factor amongst TA patients in affected regions in Europe, North America, and the Middle East. In addition to grass pollens, studies on UK events have reported on transient rises in environmental fungal spores such as Ustilago, Cladosporium, and Didymella sp. during and after the rain. ${ }^{13,42}$ A major UK event in 2000 which resulted in one death was found to be triggered by fungal spores including Alternaria, where it was reported that sensitization to Alternaria conferred a 9-fold odds ratio of developing TA $(\mathrm{OR}=9.31,95 \% \quad \mathrm{CI}=2.305-37.601)$, which 
increased if sensitized to Alternaria, Cladosporium, or both $\quad(\mathrm{OR}=63.966, \quad 95 \% \quad \mathrm{CI}=3.577-1143.9) .{ }^{43}$ Environmental fungal spores were similarly implicated in a Canadian case report. ${ }^{44}$ Cladosporium spores are 3-4 $\mu \mathrm{m}$ in diameter and would be respirable to the lower airway, whereas Alternaria spores form macroconidia with larger dimensions with a diameter of $10 \mu \mathrm{m} .{ }^{43}$ It is possible, although conjecture, that a similar meteorological process as seen in the Australian studies of RGP grain rupture occur for fungal species during ETSA events. In Italy, unique sensitization to Parietaria pollen (an urticacea weed) as well as olive tree pollen appeared to confer a risk of developing TA. ${ }^{45,46}$

\section{Immunologic Factors}

The allergic basis underpinning thunderstorm asthma pathophysiology is supported by the significant degree of RGP sensitization (mean skin prick wheal size of 10$11 \mathrm{~mm}$, mean serum $\operatorname{sigE}$ at $55 \mathrm{kUA} / \mathrm{L}$ ), and a finding of increased sputum eosinophilia, including in those who were on an ICS, in those who suffered from TA in the 2016 Melbourne event. ${ }^{33,35,47}$ The rapid onset of symptoms in TA is suggestive of mast cell degranulation and airway narrowing, as classically seen in allergic asthma. This requires individuals to be sensitized to RGP antigens through production of RGP-sIgE, which upon reexposure leads to crosslinking of $\operatorname{IgE}$ with the high affinity receptor Fc epsilon RI (FceRI) present on mast cells and basophils, leading to the production of proinflammatory mediators that promote mucosal edema, luminal mucous accumulation, and smooth muscle contraction (Figure 1). New insights into the role of $\gamma \delta \mathrm{T}$ cells have also been noted in allergic inflammatory diseases, with upregulation in the nasal mucosa including in nasal polyps, and modulation of allergic inflammation through forkhead box protein P3 (FOXP3) and IL-10. ${ }^{48,49}$ Ongoing studies into the role of $\gamma \delta$ T-cells in allergic inflammatory diseases may not only improve understanding of some of the immunologic pathophysiology in allergic asthma, but may also point to novel immunoregulatory approaches to skew individual sensitization away from a TH-2 bias.

The importance of eosinophils in TA pathogenesis is underscored by evidence of elevated IL- 5 positive cells and eosinophil numbers in the airway spaces of patients during an acute exacerbation of $\mathrm{TA},{ }^{47}$ in keeping with the inflammatory profile of TH-2 asthma. ${ }^{50}$ This mimics the airway inflammatory responses observed using allergen inhalation challenge as a clinical model for allergic asthma. ${ }^{51}$ Interleukin-5 is the key mediator in the recruitment, activation, and degranulation of eosinophils, which are critical to the pathogenesis of allergic asthma. ${ }^{52}$ Measurement of blood eosinophilia is a useful surrogate for airway eosinophilia and has proven utility in predicting eosinophilic asthma. ${ }^{53}$ However, the same cannot be said for predicting TA, as there is scant evidence to show significant differences in blood eosinophil levels when compared to other asthma phenotypes. ${ }^{35}$ Furthermore, it is not known whether peripheral blood eosinophilia correlates well with levels of eosinophils in airway spaces of TA patients.

\section{Lung Function Testing}

Lung function testing, or spirometry, is a readily available clinical tool, the results of which most clinicians are able to interpret, including the ability to potentially identify asymptomatic asthmatics in the SAR population, many of whom presented for the first time during ETSA. However, the use of spirometry on its own has not been demonstrated as an effective diagnostic tool to distinguish TA patients from other asthma patients. ${ }^{35}$

To further classify TA patients, a more specific biomarker such as fractional exhaled nitric oxide (FeNO) is needed in addition to spirometry. FeNO is increasingly used in respiratory function laboratories as a diagnostic and monitoring tool to guide treatment decisions in asthma patients, as it is an indicator of $\mathrm{TH}-2$ airway inflammation. ${ }^{54}$ FeNO levels are raised in patients with AR, with or without known asthma. ${ }^{55}$ The degree of airway inflammation as indexed by FeNO in patients who presented with ETSA was comparable to that in severe chronic asthma patients. ${ }^{35}$ At present, there is no prospective evidence on the utility of FeNO in predicting TA risk, but it may have a role in monitoring of treatment adherence and dosage guidance in asthma preventer treatment.

\section{Asthma Genomics}

Genomics data on ETSA is lacking, but precedence has been set with the identification of several susceptibility genes in genome-wide association studies (GWAS) of asthma. Previous estimations have noted that genetic predisposition accounted for $25-80 \%$ of asthma risk and up to $90 \%$ of AR risk. $^{56}$ The chromosome $17 \mathrm{q} 21$ region is the most well described and consistently replicated region with asthma susceptibility. ${ }^{57}$ ORMDL sphingolipid biosynthesis regulator 3 (ORMDL3) was the first gene identified in this region, which 


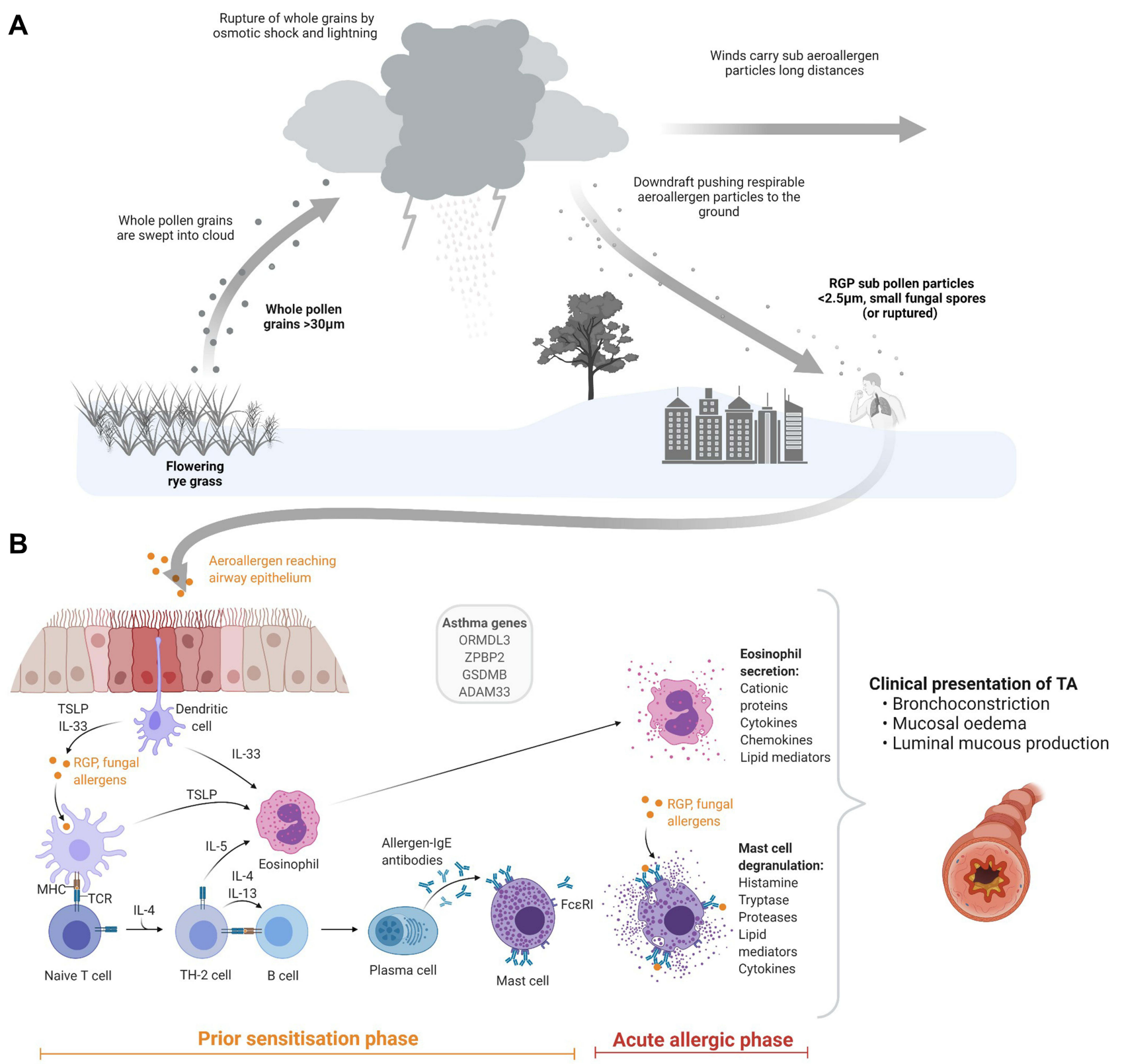

Figure I The mechanisms underlying TA. (A) In TA aeroallergens are swept into the cloud systems including whole pollen grains produced by flowering grasses and fungal elements. These are ruptured through osmotic shock and lightning activity, releasing an abundance of respirable aeroallergens. Strong winds are able to carry these particles across long distances to urban populations. Downdrafts push these particles to the ground surface for human contact. (B) A prior sensitization phase previously occurring in the respiratory airway primes the immune system for its acute allergic phase upon reintroduction. Inhaled aeroallergens are then introduced to the lower airway where they are detected by dendritic cells, which produce TSLP (in addition the respiratory epithelium) and IL-33 and present these to naïve T-cells in the lymph nodes, which switch to TH-2 cells through the influence of IL-4 and IL-I3. TH-2 cells activate B-cells via IL-4 and IL-I3, leading to plasma cells which produce allergen slgE. TH-2 cells also activate eosinophils through IL-5. Re-exposure to an aeroallergen in a sensitized individual leads to activation of eosinophils and secretion of its proinflammatory mediators, and activation of mast cells through pre-formed slgE, leading to degranulation. The clinical presentation of TA results secondary to the acute allergic phase. Part (A) and (B) were created using BioRender.com.

codes for transmembrane proteins anchored in the endoplasmic reticulum. ${ }^{58}$ Polymorphisms in this genetic region are associated with altered expression of IL-4 and IL-13 cytokine levels, both TH-2 pathway mediators. ${ }^{59}$ Other identified susceptibility genes include zona pellucida-binding protein 2 (ZPBP2) ${ }^{60}$ and gasdermin B (GSDMB). ${ }^{61}$ GSDMB was thought to be involved in epithelial cell apoptosis and upregulation of airway remodeling genes. A whole genome and ribonucleic acid sequencing study found that polymorphism in GSDMB was associated with asthma severity and exacerbations. ${ }^{57}$ Furthermore, GSDMB correlated with expression of interferon and TH-1 related antiviral pathways, suggesting a complex interaction between viral infection and subsequent asthma exacerbations. ${ }^{61}$ 
Another notable asthma candidate gene is a disintegrin and metalloprotease 33 (ADAM33) located on chromosome 20p13. ADAM33 is a susceptibility gene expressed in airway smooth muscles, fibroblasts, and mesenchymal progenitor cells, and genetic polymorphisms of this gene are associated with early childhood asthma risk. Increased levels of soluble ADAM33 in airways is linked to bronchial hyper-responsiveness and airway remodeling through non-inflammatory pathways. Experimental murine models have demonstrated the effects of inducing expression of soluble ADAM33 in utero, which promoted bronchial hyper-responsiveness and eosinophilia in postnatal life, even at low level aeroallergen exposure. ${ }^{62}$

Much progress has been made in the understanding of gene-environment interaction in asthma pathogenesis. The hygiene hypothesis of allergy prevalence was convincingly refined by studies on genetically similar European populations, the Hutterites and Amish, that migrated to the US to establish farming communities. ${ }^{63}$ The remarkable observation of a $75 \%$ reduction in atopy in Amish was ascribed to increased environmental endotoxin exposure due to low mechanization farming practices. This study highlights the need to consider gene by environment interactions. It is also known that migrant populations have increased risk of developing asthma and AR compared to the native population and interestingly this risk increases with length of stay in the host country, ${ }^{64}$ suggesting the effects of environmental exposure on susceptibility genes. This risk distinction is less clear between first and second generation migrants, with conflicting evidence. ${ }^{65}$

Recent reviews have summarized the risk variants shared between those with asthma, AR, and eczema, providing evidence for shared disease pathogenesis and elucidating the function of identified genes including major histocompatibility complex (MHC) Class II molecules, IL1 receptor like 1 (IL1RL1), and mediators of TH-2 pathways such as IL-5, IL-13, and IL-33. ${ }^{66}$ Nevertheless, further studies on the genetics of TA are needed to provide insight into risk and severity prediction, and highlight the role and potential for personalized medicine.

\section{Clinical and Severity Risk Factors}

There is an increasing body of evidence characterizing clinical risk factors for severe asthma in TA. The largest analysis on ETSA was from the 2016 Melbourne event which clearly identified that there are distinct gradients of risk. For Australian individuals, there is an increased risk of TA in individuals of Asian ethnicity born in Australia, suggesting a genetic predisposition, with an odds ratio of 5.4 for TA-related hospital admission. ${ }^{1}$ Of the total number of ETSA presentations at the ED, 39\% were of Indian or Asian ethnicity. ${ }^{1}$ The degree of sensitization to RGP, and to Lol p 5, confers the greatest risk of TA, with $87 \%$ of patients presenting to the ED having a diagnosis of SAR. ${ }^{1,8}$ Pre-existing asthma is not identified as a risk factor for all individuals affected by TA, but has been associated with severity, with an odds ratio of 1.9 for hospital admission, and for those who required intensive care unit support (35 patients) or died due to TA (10 patients) there was a prior history of asthma. ${ }^{1}$ In these cases with known asthma, there was likely uncontrolled airway inflammation with a history of poor disease control, as reflected by prior asthma-related hospital admission and ICS adherence. ${ }^{4}$ It is thought that the majority of affected individuals have mild symptoms and do not selfpresent for healthcare assistance, as noted in a survey of health care workers, with $25 \%$ having asthma symptoms during the 2016 Melbourne event. ${ }^{67}$

\section{Management}

\section{ETSA Preparedness and Risk Reduction}

A key lesson of the Melbourne thunderstorm asthma epidemic was its framing of ETSA risk for individuals without known airways disease. Prior to November 2016, it was established that $36-44 \%$ of those affected by ETSA epidemics had not been formally diagnosed with asthma. ${ }^{27,68}$ In the Melbourne event, this figure was up to $60 \%,{ }^{4,33}$ highlighting both the need to broadly expand target populations for counseling in ETSA preparedness and risk reduction and the prevalence of undiagnosed asthma in the community.

It is now known that SAR alone is a risk factor for thunderstorm asthma, under certain meteorological conditions. Affected individuals should therefore be instructed on behavioral interventions: most importantly, avoiding exposure to the outdoors environment in the hours leading up to a thunderstorm and monitoring local grass pollen counts when possible. Clinicians must also perform a targeted history to elicit features suspicious of undiagnosed asthma, in order to identify those with occult disease. Retrospective reviews indicate that this group constituted $25-46 \%$ of ETSA affected patients in the Melbourne event. ${ }^{4,33}$

The National Asthma Council of Australia recommends that individuals with asthma at risk of ETSA be 
given a written Asthma Action Plan, reliever, and preventer (either regular ICS and as-needed short acting beta agonist [SABA], or as-needed low dose budesonide/formoterol). Those not on year-round ICS treatment should commence one of the above preventer strategies in the lead-up to pollen season ( 2 weeks before at a minimum) and continue it throughout the period of peak airborne allergen load. ${ }^{69}$

\section{Choice of Inhaled Therapy}

It is well established that SABA-only treatment is suboptimal therapy for prevention of asthma exacerbations. $^{70,71}$ However, the choice between asneeded ICS/LABA combination treatment and continuous ICS plus as-needed SABA is contentious. The first strategy seems likely to improve treatment adherence, particularly in individuals with intermittent symptoms (who are presumed to represent a significant proportion of "at-risk" TA patients).

A post-hoc analysis of the Symbicort Given as-needed in Mild Asthma study (SYGMA1) found that as-needed budesonide-formoterol had similar efficacy to maintenance ICS in reducing the frequency of SABA use and risk of subsequent exacerbations. ${ }^{72}$ However, there is stronger long-term data on use of regular ICS or ICS/LABA in prevention of asthma-related morbidity and mortality. ${ }^{73,74}$ Furthermore, it remains unclear whether the "as-needed" strategy is superior with regard to symptom control and exacerbation prevention, creating an area of ambiguity for TA management. Nevertheless, the rapid onset of bronchodilator action of formoterol makes it well suited to provide acute relief in TA, whereas the concurrent ICS dosing from a combination therapy may limit on-going impacts of the acute episode of asthma.

\section{Novel Approaches to Prevention Immunotherapy}

Given the strong link between aeroallergen sensitization and inflammatory airway changes underlying TA, allergen desensitization (immunotherapy) presents an intriguing opportunity to both treat SAR and reduce allergic asthma exacerbations. Systematic review has demonstrated that immunotherapy reduces asthma symptoms, potentially to the same extent as inhaled steroids. ${ }^{75}$ A recent controlled trial of pre-seasonal grass pollen sublingual immunotherapy (SLIT) in 34 subjects with SAR found that SLIT was protective for the 2016 Melbourne ETSA event: no SLIT patients reported an asthma exacerbation on that day, compared with $41 \%$ (7/17) of pharmacotherapy-only patients. ${ }^{76}$ However, prospective larger-scale studies are lacking and will be difficult to power given the rarity and unpredictability of ETSA events, although given the increased frequency of asthma in those with SAR, studies of the utility of grass pollen SLIT in preventing asthma morbidity or signs during the spring season would be valuable indicators of likely efficacy.

\section{Leukotriene Antagonists}

To date, research on use of leukotriene antagonists for prevention of seasonal asthma has largely been focused on children and results have been mixed. It was initially reported that montelukast plus standard care reduces risk of worsening asthma symptoms and unscheduled physician visits during the annual peak asthma season for school children (September in North America). ${ }^{77}$ Pranlukast seemed to have a similar benefit, particularly among boys aged $1-5$ years. ${ }^{78}$ However, a subsequent larger study found that montelukast was not associated with a significant reduction in missed days of school due to asthma. ${ }^{79}$ The exceptionally high level of allergen exposure and the temporally discrete activation of mast cells in TA could be expected to increase the significance of the acute actions of cysteinyl leukotrienes in the ensuing airway obstruction. The aforementioned studies provide only indirect guidance as to the potential of this drug class.

\section{Biologics}

The advent of biologic therapies for difficult-to-control asthma has revolutionized respiratory medicine. Currently, four asthma biologics have Therapeutic Goods Administration approval in Australia for severe asthma. Each biologic has been shown to reduce systemic steroid use, ED visits, and hospitalization. ${ }^{80}$ These treatments are targeted towards a TH-2 asthma phenotype, which clearly correlates with the risk profile for SAR with TA. Furthermore, the anti-IgE medication omalizumab has been shown to have increased benefit in autumn and spring (compared with summer months) across all age groups in individuals with allergic asthma in the US. ${ }^{81}$

However, the use of biologic asthma therapies for prevention of intermittent allergic asthma and TA specifically is not established and they are indicated for chronic severe asthma requiring continuous use rather than to prevent episodic asthma. Given the cost and inconvenience of these medications, further research is needed to accurately stratify TA risk; thus enabling targeted treatment for the 
most susceptible individuals. Short-term pre-seasonal use of asthma biologics may prove to be an economically sound and effective strategy to prevent seasonal exacerbations of allergic asthma, including TA in selected patients. Evidence to support the abbreviated use of anti-IgE is found in a North American study of pre-seasonal (3-month) omalizumab for prevention of autumn asthma exacerbations in inner-city children. In this cohort, exacerbations were reduced by $52 \%$ in the omalizumab treatment arm compared to placebo. $^{82}$

\section{Environmental Health Literacy}

Whilst the triggers and risk factors for TA are reasonably well established, a question arises as to what might be done to mitigate the effects of TA in the community? Ensuring the availability of emergency warnings and treatments for those affected by TA has been the focus of major public health initiatives in Victoria since 2016. The initiation of preventive physical strategies as well as therapies for TA in those who suffer from SAR might also be implemented at an individual level by an understanding of risk factors for TA, but this depends on the capacity of individuals and communities to recognize and act to mitigate such risks. The capacity to recognize and act on environmental threats to health is measured as Environmental Health Literacy (EHL) ${ }^{83}$

EHL can be defined as a strategy that can enable individuals and communities to moderate environmental exposures that pose a risk to health outcomes. ${ }^{84} \mathrm{EHL}$ in its substantive context embraces community and socioeconomic diversity in a hierarchy of knowledge and empowerment to recognize, understand, analyze, evaluate, and respond to environmental health risks to enable and inform mitigation strategies. Importantly, EHL intersects with public and professional communication and education strategies regarding environmental threats and recognizes the diversity between individuals and within communities that challenges effective communication strategies and mandates community involvement to enable effective solutions to be devised. ${ }^{85}$

One strategy to inform the community of approaching risk for TA is through emergency warning systems. Following the 2016 event the Victorian State Government established a pollen monitoring and warning system measured from several sentinel pollen monitoring stations in the State. Information was distributed through the Melbourne Pollen Count publicized through an available website and smartphone app (www.melbournepollen.com.au) and further publicized through generic warning systems such as the state emergency services and weather advice apps, and weather reports distributed in public media. ${ }^{86}$ The Melbourne Pollen App provides pollen counts, advice, and warnings for risks for thunderstorm asthma based on statewide pollen counts and meteorological modeling to estimate the future risk of pollen-induced thunderstorm asthma events, or "high-asthma admission days". ${ }^{87}$ The capacity of individuals to respond to such advice is determined by e-health literacy, relying on the capacity of individuals and communities to access e-health and media information and warnings to influence health knowledge seeking behavior and to implement its advice. ${ }^{88}$ The internet and Google searches might also be considered a warning system per se, with the Google trends data for searches for "asthma" in Melbourne in relation to the 2016 TA epidemic and Kuwait during episodes of epidemic asthma clearly demonstrating a peak in the searches compared to seasonal asthma. ${ }^{89}$ Evidently the community at large made use of the internet to seek advice in the event of thunderstorm asthma, a fact that might be used to provide advice in the likely event of recurrence.

At an individual level, recognition of the threats and risk of TA might inform individual behaviors such as ensuring adherence to preventing therapies, maintaining a supply of asthma medication, and ensuring emergency plans for asthma are in place. Health literacy generally and EHL in particular might also enable such preventive strategies as recognition of the threat and staying indoors at the time of thunderstorm passing overhead and recognizing the likely weather events preceding a thunderstorm asthma event to inform decisions regarding travel and being outdoors. It is notable that the majority of TA events in Victoria have occurred in the setting of an evening thunderstorm coinciding with evening peak-hour when people are more likely to be outdoors whilst traveling home from work, thereby exposing individuals to the risks of a pollen-laden storm-front whilst in transit outdoors. $^{3}$ Importantly, communication of such risks must be culturally and demographically appropriate to maximize individual understanding and maximize impacts on behaviors. ${ }^{84}$ Information that enables accurate risk determination at an individual level might also inform health providers of the importance of environmental health threats, enabling appropriate emphasis to advise those at greatest risk and inform medical planning of medical interventions and ensure that such advice is targeted and the investment of individual 
education made most productively. ${ }^{23}$ Appreciation of an individual's health risks must also be cognizant of the significant association of lower education and socioeconomic status with risk factors for asthma mortality. ${ }^{90}$ Addressing such barriers will require a systematic approach.

\section{Summary}

TA events have historically occured unexpectedly, causing an inundation to health care services that have prompted improvements in the understanding of its mechanistic underpinnings. Our understanding of the management of TA has significantly improved in recent times with a large body of health and environmental research supporting the mechanistic factors responsible for its occurrence. The most common identified aeroallergens include RGP and fungi, however consideration should not be restricted to these factors as it is likely that the combination of prior sensitization and exposure to respirable particles is required to cause thunderstorm asthma. Management can include both public health strategies and individual treatment advice. Early warning systems related to meteorological factors and improved awareness through EHL will reduce the overall burden of affected individuals. The challenge remains difficult for risk identification for prevention strategies in at risk individuals. Patients who have known asthma should have optimization of asthma preventive treatments and adherence to ICS during the at-risk seasons promoted, noting that adherence to regular preventive therapies in asthma is often inadequate and improvements in health education are important to raise awareness. Precision treatment with immunological approaches can be utilized, including allergen-specific immunotherapy, which has its own financial and duration constraints, and whilst currently without evidence, biologic agents might be considered as pre-seasonal therapy to prevent severe TA episodes in those most at risk. With predictions of more frequent events due to climate change, awareness and preparedness need to improve, including in regions previously unaffected. Further research is required to understand the mechanisms of TA, possible biomarkers for risk stratification, and inform improvements in targeted treatment approaches.

\section{Disclosure}

JC and JAT have no relevant affiliations or financial involvement with any organization or entity with a financial interest in or financial conflict with the subject matter or materials discussed in the manuscript, which includes employment, consultancies, honoraria, stock ownership or options, expert testimony, grants or patents received or pending, or royalties. SC reports grants from the Medical Research Future Fund during the conduct of related studies; grants, personal fees and non-financial support from CSL and non-financial support from Sanofi outside the submitted work. AGS reports grants from CSL Ltd, outside the submitted work. JAD has received funding to support this work from the Medical Research Future Fund's Rapid Applied Research Translation program in conjunction with the Melbourne Academic Centre for Health. In the past 5 years, she has received honoraria for educational presentations from Astra-Zeneca, GSK, Novartis, Alphapharm, Shire, CSL. She has served on advisory boards: SanofiAventis, Novartis, GSK, Astra-Zeneca, Shire, Immunosis, and CSL. She has undertaken contracted or investigatorinitiated research on behalf of: GSK, Novartis, Immunosis, AstraZeneca, Sanofi-Aventis, Grifols, CSL, BioCryst, and Equilium. She has a personal superannuation shareholding in CSL. The authors report no other conflicts of interest in this work.

\section{References}

1. Hew M, Lee J, Susanto NH, et al. The 2016 Melbourne thunderstorm asthma epidemic: risk factors for severe attacks requiring hospital admission. Allergy Eur J Allergy Clin Immunol. 2019;74(1):122-130. doi:10.1111/all.13609

2. Thien F. Melbourne epidemic thunderstorm asthma event 2016: lessons learnt from the perfect storm. Respirology. 2018;23(11):976-977. doi:10.1111/resp. 13410

3. Harun NS, Lachapelle P, Douglass J. Thunderstorm-triggered asthma: what we know so far. J Asthma Allergy. 2019;12:101-108. doi:10.2147/JAA.S175155

4. Thien F, Beggs PJ, Csutoros D, et al. The Melbourne epidemic thunderstorm asthma event 2016: an investigation of environmental triggers, effect on health services, and patient risk factors. Lancet Planet Heal. 2018;2(6):e255-e263. doi:10.1016/S2542-5196(18)30120-7

5. Hew M, Sutherland M, Thien F, O'Hehir R. The Melbourne thunderstorm asthma event: can we avert another strike? Intern Med J. 2017;47(5):485-487. doi:10.1111/imj.13413

6. Thien F, Davies JM, Hew M, Douglass JA, O'Hehir RE. Thunderstorm asthma: an overview of mechanisms and management strategies. Expert Rev Clin Immunol. 2020;16(10):1005-1017. doi:10.1080/ 1744666X.2021.1826310

7. Price D, Hughes KM, Thien F, Suphioglu C. Epidemic thunderstorm asthma: lessons learned from the storm down-under. J Allergy Clin Immunol Pract. 2021;9(4):1510-1515. doi:10.1016/j.jaip.2020.10.022

8. Hew M, Lee J, Varese N, et al. Epidemic thunderstorm asthma susceptibility from sensitization to ryegrass (Lolium perenne) pollen and major allergen Lol p 5. Allergy Eur J Allergy Clin Immunol. 2020;75 (9):2369-2372. doi:10.1111/all.14319

9. Emmerson KM, Silver JD, Thatcher M, et al. Atmospheric modelling of grass pollen rupturing mechanisms for thunderstorm asthma prediction. PLoS One. 2021;16(4):e0249488. doi:10.1371/journal. pone. 0249488 
10. Cecchi L, Scala E, Caronni S, Citterio S, Asero R. Allergenicity at component level of sub-pollen particles from different sources obtained by osmolar shock: a molecular approach to thunderstorm-related asthma outbreaks. Clin Exp Allergy. 2021;51(2):253-261. doi:10.1111/cea.13764

11. de Morton J, Bye J, Pezza A, Newbigin E. On the causes of variability in amounts of airborne grass pollen in Melbourne, Australia. Int J Biometeorol. 2011;55(4):613-622. doi:10.1007/ s00484-010-0361-x

12. Hughes DD, Mampage CBA, Jones LM, Liu Z, Stone EA. Characterization of atmospheric pollen fragments during springtime thunderstorms. Environ Sci Technol Lett. 2020;7 (6):409-414. doi:10.1021/acs.estlett.0c00213

13. Packe GE, Ayres JG. Asthma outbreak during a thunderstorm. Lancet. 1985;326(8448):199-204. doi:10.1016/S0140-6736(85) 91510-7

14. Nemery B, Hoet PHM, Nemmar A. The Meuse Valley fog of 1930: an air pollution disaster. Lancet. 2001;357(9257):704-708. doi:10.1016/S0140-6736(00)04135-0

15. Jacobs ET, Burgess JL, Abbott MB. The Donora smog revisited: 70 years after the event that inspired the clean air act. Am J Public Health. 2018;108(S2):S85-S88. doi:10.2105/AJPH.2017.304219

16. Logan WPD. Mortality in the London fog incident, 1952. Lancet. 1953;261(6755):336-338. doi:10.1016/S0140-6736(53)91012-5

17. Mendes E, Cintra AU. Collective asthma, simulating an epidemic, provoked by castor-bean dust. J Allergy. 1954;25(3):253-259. doi:10.1016/0021-8707(54)90183-5

18. Girsh LS, Shubin E, Dick C, Schulaner FA. A study on the epidemiology of asthma in children in Philadelphia. The relation of weather and air pollution to peak incidence of asthmatic attacks. $J$ Allergy. 1967;39(6):347-357. doi:10.1016/00218707(67)90047-0

19. Grundstein A, Sarnat SE, Klein M, et al. Thunderstorm associated asthma in Atlanta, Georgia. Thorax. 2008;63(7):659-660. doi:10.1136/thx.2007.092882

20. Villeneuve PJ, Leech J, Bourque D. Frequency of emergency room visits for childhood asthma in Ottawa, Canada: the role of weather. Int $J$ Biometeorol. 2005;50(1):48-56. doi:10.1007/ s00484-005-0262-6

21. Idani E, Dastoorpoor M, Goudarzi G, Khanjani N. Severe outbreaks of respiratory syndromes following autumn rainfall in Khuzestan, Iran. Arch Iran Med. 2016;19(12):884-885.

22. Bannister T, Csutoros D, Arnold AL, et al. Are convergence lines associated with high asthma presentation days? A case-control study in Melbourne, Australia. Sci Total Environ. 2020;737:140263. doi:10.1016/j.scitotenv.2020.140263

23. Cecchi L, D'Amato G, Annesi-Maesano I. External exposome and allergic respiratory and skin diseases. J Allergy Clin Immunol. 2018;141(3):846-857. doi:10.1016/j.jaci.2018.01.016

24. Global Initiative For Asthma. GINA full report 2021 [webpage on the internet]. Available from: https:/ginasthma.org/wp-content /uploads/2021/05/GINA-Main-Report-2021-V2-WMS.pdf. Accessed June 9, 2021.

25. Marks GB, Bush RK. It's blowing in the wind: new insights into thunderstorm-related asthma. J Allergy Clin Immunol. 2007;120 (3):530-532. doi:10.1016/j.jaci.2007.07.012

26. D'Amato G, Chong-Neto HJ, Monge Ortega OP, et al. The effects of climate change on respiratory allergy and asthma induced by pollen and mold allergens. Allergy Eur J Allergy Clin Immunol. 2020;75(9):2219-2228. doi:10.1111/all.14476

27. Girgis ST, Marks GB, Downs SH, Kolbe A, Car GN, Paton R. Thunderstorm-associated asthma in an inland town in south-eastern Australia. Who is at risk? Eur Respir J. 2000;16 (1):3-8. doi:10.1034/j.1399-3003.2000.16a02.x
28. Marks GB, Colquhoun JR, Girgis ST, et al. Thunderstorm outflows preceding epidemics of asthma during spring and summer. Thorax. 2001;56(6):468-471. doi:10.1136/thx.56.6.468

29. Edginton S, O'Sullivan DE, King WD, Lougheed MD. The effect of acute outdoor air pollution on peak expiratory flow in individuals with asthma: a systematic review and meta-analysis. Environ Res. 2021;192:110296. doi:10.1016/j.envres.20 20.110296

30. Howden ML, McDonald CF, Sutherland MF. Thunderstorm asthma - a timely reminder. Med J Aust. 2011;195(9):512-513. doi:10.5694/mja11.11044

31. Zanocco C, Boudet H, Nilson R, Satein H, Whitley H, Flora J. Place, proximity, and perceived harm: extreme weather events and views about climate change. Clim Change. 2018;149(34):349-365. doi:10.1007/s10584-018-2251-x

32. D'Amato G, Akdis CA. Global warming, climate change, air pollution and allergies. Allergy Eur J Allergy Clin Immunol. 2020;75(9):2158-2160. doi:10.1111/all.14527

33. Lee J, Kronborg C, O'Hehir RE, Hew M. Who's at risk of thunderstorm asthma? The ryegrass pollen trifecta and lessons learnt from the Melbourne thunderstorm epidemic. Respir Med. 2017;132:146-148. doi:10.1016/j.rmed.2017.10.012

34. Bellomo R, Gigliotti P, Treloar A, et al. Two consecutive thunderstorm associated epidemics of asthma in the city of Melbourne. The possible role of rye grass pollen. Med J Aust. 1992;156 (12):834-837. doi:10.5694/j.1326-5377.1992.tb136994.x

35. Sutherland MF, Le Portelli E, Collins AL, Rahman MA, Mcdonald CF. Patients with thunderstorm asthma or severe asthma in Melbourne: a comparison. Med J Aust. 2017;207 (10):434-435. doi:10.5694/mja17.00780

36. Erbas B, Akram M, Dharmage S, et al. The role of seasonal grass pollen on childhood asthma emergency department presentations. $J$ Allergy Clin Immunol. 2012;129(2):AB166. doi:10.1016/j. jaci.2011.12.382

37. Ford SA, Baldo BA. A re-examination of ryegrass (Lolium perenne) pollen allergens. Int Arch Allergy Appl Immunol. 1986;81 (3):193-203. doi:10.1159/000234134

38. Ong EK, Singh MB, Knox RB. Grass pollen in the atmosphere of Melbourne: seasonal distribution over nine years. Grana. 1995;34 (1):58-63. doi:10.1080/00173139509429034

39. Ongv EK, Griffith IJ, Knox RB, Singh MB. Cloning of a cDNA encoding a group-V (group-IX) allergen isoform from rye-grass pollen that demonstrates specific antigenic immunoreactivity. Gene. 1993;134(2):235-240. doi:10.1016/0378-1119(93)90099-O

40. Staff IA, Schäppi G, Taylor PE. Localisation of allergens in ryegrass pollen and in airborne micronic particles. Protoplasma. 1999;208(1-4):47-57. doi:10.1007/BF01279074

41. Suphioglu C, Singh MB, Taylor P, et al. Mechanism of grass-pollen-induced asthma. Lancet. 1992;339(8793):569-572. doi:10.1016/0140-6736(92)90864-Y

42. Allitt U. Airborne fungal spores and the thunderstorm of 24 June 1994. Aerobiologia. 2000;16(3-4):397-406. doi:10.1023/ A: 1026503500730

43. Pulimood TB, Corden JM, Bryden C, Sharples L, Nasser SM. Epidemic asthma and the role of the fungal mold Alternaria alternata. $J$ Allergy Clin Immunol. 2007;120(3):610-617. doi:10.1016/j.jaci.2007.04.045

44. Wardman AD, Stefani D, MacDonald JC. Thunderstormassociated asthma or shortness of breath epidemic: a Canadian case report. Can Respir J. 2002;9(4):267-270. doi:10.1155/2002/ 728257

45. D'Amato G, Cecchi L, Liccardi G. Thunderstorm-related asthma: not only grass pollen and spores. J Allergy Clin Immunol. 2008;121(2):537-538. doi:10.1016/j.jaci.2007.10.046 
46. Losappio L, Heffler E, Contento F, Cannito C, Rolla G. Thunderstorm-related asthma epidemic owing to Olea Europaea pollen sensitization. Allergy Eur J Allergy Clin Immunol. 2011;66 (11):1510-1511. doi:10.1111/j.1398-9995.2011.02699.x

47. Wark PAB, Simpson J, Hensley MJ, Gibson PG. Airway inflammation in thunderstorm asthma. Clin Exp Allergy. 2002;32 (12):1750-1756. doi:10.1046/j.1365-2222.2002.01556.x

48. Zheng R, Yang Q. The role of the $\gamma \delta \mathrm{T}$ cell in allergic diseases. J Immunol Res. 2014;5:1-8.

49. Yang Q, Li C, Wang W, et al. Infiltration pattern of gammadelta $\mathrm{T}$ cells and its association with local inflammatory response in the nasal mucosa of patients with allergic rhinitis. Int Forum Allergy Rhinol. 2019;9(11):1318-1326. doi:10.1002/alr.22421

50. Kuruvilla ME, Lee FEH, Lee GB. Understanding asthma phenotypes, endotypes, and mechanisms of disease. Clin Rev Allergy Immunol. 2019;56(2):219-233. doi:10.1007/s12016-018-8712-1

51. Gauvreau G, El-Gammal A, O’Byrne P. Allergen-induced airway responses. Eur Respir J. 2015;46(3):819-831. doi:10.1183/ 13993003.00536-2015

52. McBrien CN, Menzies-Gow A. The biology of eosinophils and their role in asthma. Front Med. 2017;4(93):1-14. doi:10.3389/ fmed.2017.00093

53. Wagener AH, De Nijs SB, Lutter R, et al. External validation of blood eosinophils, FENO and serum periostin as surrogates for sputum eosinophils in asthma. Thorax. 2015;70(2):115-120. doi:10.1136/thoraxjnl-2014-205634

54. Menzies-Gow A, Mansur AH, Brightling CE. Clinical utility of fractional exhaled nitric oxide in severe asthma management. Eur Respir J. 2020;55(3):1901633. doi:10.1183/13993003.016332019

55. Kalpaklioglu AF, Kalkan IK. Comparison of orally exhaled nitric oxide in allergic versus nonallergic rhinitis. Am J Rhinol Allergy. 2012;26(2):e50-e54.

56. Laulajainen-Hongisto A, Lyly A, Hanif T, et al. Genomics of asthma, allergy and chronic rhinosinusitis: novel concepts and relevance in airway mucosa. Clin Transl Allergy. 2020;10 (1):1-17. doi:10.1186/s13601-020-00347-6

57. Wan YI, Shrine NRG, Soler Artigas M, et al. Genome-wide association study to identify genetic determinants of severe asthma. Thorax. 2012;67(9):762-768. doi:10.1136/thoraxjnl2011-201262

58. Moffatt MF, Kabesch M, Liang L, et al. Genetic variants regulating ORMDL3 expression contribute to the risk of childhood asthma. Nature. 2007;448(7152):470-473. doi:10.1038/ nature 06014

59. Schedel M, Michel S, Gaertner VD, et al. Polymorphisms related to ORMDL3 are associated with asthma susceptibility, alterations in transcriptional regulation of ORMDL3, and changes in $\mathrm{TH} 2$ cytokine levels. J Allergy Clin Immunol. 2015;136(4):893-903. e14. doi:10.1016/j.jaci.2015.03.014

60. Nieuwenhuis MA, Siedlinski $M$, van den Berge $M$, et al Combining genomewide association study and lung eQTL analysis provides evidence for novel genes associated with asthma. Allergy Eur J Allergy Clin Immunol. 2016;71(12):1712-1720. doi:10.1111/all.12990

61. Li X, Christenson SA, Modena B, et al. Genetic analyses identify GSDMB associated with asthma severity, exacerbations, and antiviral pathways. J Allergy Clin Immunol. 2021;147(3):894-909. doi:10.1016/j.jaci.2020.07.030

62. Davies ER, Kelly JFC, Howarth PH, et al. Soluble ADAM33 initiates airway remodeling to promote susceptibility for allergic asthma in early life. JCI Insight. 2016;1(11). doi:10.1172/jci. insight. 87632

63. Stein MM, Hrusch CL, Gozdz J, et al. Innate immunity and asthma risk in amish and hutterite farm children. $N$ Engl J Med. 2016;375(5):411-421. doi:10.1056/NEJMoa1508749
64. Leung RC, Carlin JB, Burdon JGW, Czarny D. Asthma, allergy and atopy in Asian immigrants in Melbourne. Med J Aust. 1994;161(7):418-425. doi:10.5694/j.1326-5377.1994.tb127522.x

65. Tham EH, Loo EXL, Zhu Y, Shek LPC. Effects of migration on allergic diseases. Int Arch Allergy Immunol. 2019;178 (2):128-140. doi:10.1159/000494129

66. Hernandez-Pacheco N, Pino-Yanes M, Flores C. Genomic predictors of asthma phenotypes and treatment response. Front Pediatr. 2019;7(5):6. doi:10.3389/fped.2019.00006

67. Clayton-Chubb D, Con D, Rangamuwa K, Taylor D, Thien F, Wadhwa V. Thunderstorm asthma: revealing a hidden at-risk population. Intern Med J. 2019;49(1):74-78. doi:10.1111/ imj. 13800

68. Davidson AC, Emberlin J, Cook AD, et al. A major outbreak of asthma associated with a thunderstorm: experience of accident and emergency departments and patients' characteristics. $\mathrm{Br}$ Med J. 1996;312(7031):601-604. doi:10.1136/bmj.312.7031.601

69. National Asthma Council. Preventing thunderstorm asthma in individuals [website on the internet]. Available from: https:// www.asthmahandbook.org.au/clinical-issues/thunderstormasthma/thunderstorm-triggered-asthma. Accessed May 30, 2021.

70. Beasley R, Holliday M, Reddel HK, et al. Controlled trial of budesonide-formoterol as needed for mild asthma. $N \mathrm{Engl}$ J Med. 2019;380(21):2020-2030. doi:10.1056/NEJMoa1901963

71. Dahlén B, Lantz AS, Ihre E, et al. Effect of formoterol with or without budesonide in repeated low-dose allergen challenge. Eur Respir J. 2009;33(4):747-753. doi:10.1183/09031936.00095508

72. O'Byrne PM, FitzGerald JM, Bateman ED, et al. Effect of a single day of increased as-needed budesonide-formoterol use on short-term risk of severe exacerbations in patients with mild asthma: a post-hoc analysis of the SYGMA 1 study. Lancet Respir Med. 2021;9(2):149-158. doi:10.1016/S2213-2600(20) 30416-1

73. Sadatsafavi M, Lynd LD, Marra CA, FitzGerald JM. Dispensation of long-acting $\beta$ agonists with or without inhaled corticosteroids, and risk of asthmarelated hospitalisation: a population-based study. Thorax. 2014;69(4):328-334. doi:10.1136/thoraxjnl-2013203998

74. Suissa S, Ernst P, Benayoun S, Baltzan M, Cai B. Low-dose inhaled corticosteroids and the prevention of death from asthma. $N$ Engl J Med. 2000;343(5):332-336. doi:10.1056/ NEJM200008033430504

75. Abramson MJ, Puy RM, Weiner JM. Injection allergen immunotherapy for asthma. Cochrane Database Syst Rev. 2010;8.

76. O'Hehir RE, Varese NP, Deckert K, et al. Epidemic thunderstorm asthma protection with five-grass pollen tablet sublingual immunotherapy: a clinical trial. Am J Respir Crit Care Med. 2018;198 (1):126-128. doi:10.1164/rccm.201711-2337LE

77. Johnston NW, Mandhane PJ, Dai J, et al. Attenuation of the September epidemic of asthma exacerbations in children: a randomized, controlled trial of montelukast added to usual therapy. Pediatrics. 2007;120(3):e702-e712. doi:10.1542/ peds.2006-3317

78. Morita Y, Campos Alberto E, Suzuki S, et al. Pranlukast reduces asthma exacerbations during autumn especially in 1- to 5-year-old boys. Asia Pac Allergy. 2017;7(1):10. doi:10.5415/ apallergy.2017.7.1.10

79. Weiss KB, Gern JE, Johnston NW, et al. The back to school asthma study: the effect of montelukast on asthma burden when initiated prophylactically at the start of the school year. Ann Allergy, Asthma Immunol. 2010;105(2):174-181. doi:10.1016/j. anai.2010.04.018

80. Doroudchi A, Pathria M, Modena BD. Asthma biologics: comparing trial designs, patient cohorts and study results. Ann Allergy, Asthma Immunol. 2020;124(1):44-56. doi:10.1016/j. anai.2019.10.016 
81. Szefler SJ, Raphiou I, Zeiger RS, Stempel D, Kral K, Pascoe S. Seasonal variation in asthma exacerbations in the AUSTRI and VESTRI studies. ERJ Open Res. 2019;5(2):00153-02018. doi:10.1183/23120541.00153-2018

82. Teach SJ, Gill MA, Togias A, et al. Preseasonal treatment with either omalizumab or an inhaled corticosteroid boost to prevent fall asthma exacerbations. J Allergy Clin Immunol. 2015;136 (6):1476-1485. doi:10.1016/j.jaci.2015.09.008

83. Lichtveld MY, Covert HH, Sherman M, Shankar A, Wickliffe JK, Alcala CS. Advancing environmental health literacy: validated scales of general environmental health and environmental media-specific knowledge, attitudes and behaviors. Int $J$ Environ Res Public Health. 2019;16(21):4157. doi:10.3390/ijerph16214157

84. Finn S, O'Fallon L. The emergence of environmental health literacy - from its roots to its future potential. Environ Health Perspect. 2017;125(4):495-501. doi:10.1289/ehp.1409337

85. Ramírez AS, Ramondt S, Van Bogart K, Perez-Zuniga R. Public awareness of air pollution and health threats: challenges and opportunities for communication strategies to improve environmental health literacy. J Health Commun. 2019;24(1):75-83. doi:10.1080/10810730.2019.1574320

86. The University of Melbourne. Melbourne pollen count and forecast [homepage on the internet]. Available from: https://www. melbournepollen.com.au/. Accessed June 2, 2021.

87. Silver JD, Sutherland MF, Johnston FH, et al. Seasonal asthma in Melbourne, Australia, and some observations on the occurrence of thunderstorm asthma and its predictability. PLoS One. 2018;13 (4):e0194929. doi:10.1371/journal.pone.0194929

88. Zhou J, Fan T. Understanding the factors influencing patient e-health literacy in online health communities (OHCs): a social cognitive theory perspective. Int J Environ Res Public Health. 2019;16(14):2455

89. Bousquet J, O'Hehir RE, Anto JM, et al. Assessment of thunderstorm-induced asthma using google trends. J Allergy Clin Immunol. 2017;140(3):891-893.e7. doi:10.1016/j.jaci.2017.04.042

90. Sinharoy A, Mitra S, Mondal P. Socioeconomic and environmental predictors of asthma-related mortality. J Environ Public Health. 2018;2018. doi:10.1155/2018/9389570

91. Alderman PM, Sloan JP, Basran GS. Asthma and thunderstorms. Arch Emerg Med. 1986;3(4):260-262. doi:10.1136/emj.3.4.260

92. Egan P. Weather or not. Med J Aust. 1985;142(5):330. doi:10.5694/j.1326-5377.1985.tb113389.x

93. Queensland University of Technology for the Department of Health and Human Services [website on the internet]. Literature review on thunderstorm asthma and its implications for public health advice. 2017. Available from: https:/www2.health.vic.gov. au/about/publications/researchandreports/thunderstorm-asthmaliterature-review-may-2107. Accessed May 28, 2021.
94. Waters J, Corbett S, Gibson P, Hensley M, Wlodarczyk J. Epidemic asthma surveillance in the New England Region 1990-1992. NSW Public Heal Bull. 1993;4(9):100-101. doi:10.1071/NB93049

95. Al-Rubaish AM. Thunderstorm-associated bronchial asthma: a forgotten but very present epidemic. J Fam Community Med. 2007;14(2):47-51.

96. Levy ML. Thunderstorm asthma. Br J Prim Care Nurs. 2007;1:69-71.

97. Elliot AJ, Hughes HE, Hughes TC, et al. The impact of thunderstorm asthma on emergency department attendances across London during July 2013. Emerg Med J. 2014;31(8):675-678. doi:10.1136/emermed-2013-203122

98. Forouzan A, Masoumi K, Haddadzadeh Shoushtari M, et al. An overview of thunderstorm-associated asthma outbreak in Southwest of Iran. $J$ Environ Public Health. 2014;2014. doi:10.1155/2014/504017

99. Colley C. Canberra sneezes through worst hay fever season in years. The Canberra Times. 2014 Nov 7.

100. Ali F, Behbehani N, Alomair N, Taher A. Fatal and near-fatal thunderstorm asthma epidemic in a desert country. Ann Thorac Med. 2019;14(2):155-160. doi:10.4103/atm.ATM 25818

101. Rad HD, Assarehzadegan MA, Goudarzi G, et al. Do Conocarpus erectus airborne pollen grains exacerbate autumnal thunderstorm asthma attacks in Ahvaz, Iran? Atmos Environ. 2019;213 (15):311-325. doi:10.1016/j.atmosenv.2019.06.010

102. Yair Y, Yair Y, Rubin B, et al. First reported case of thunderstorm asthma in Israel. Nat Hazard Earth Sys. 2019;19(12):2715-2725. doi:10.5194/nhess-19-2715-2019

103. Rabiee S, Mousavi H, Khafaie MA. Thunderstorm asthma outbreak, a rare phenomenon in southwest Iran: patient's perspectives. Environ Sci Pollut Res. 2018;25:36158-36162. doi:10.1007/s11356-018-3478-9

104. Xu YY, Xue T, Li HR, et al. Retrospective analysis of epidemic thunderstorm asthma in children in Yulin, northwest China. Pediatr Res. 2021;89:958-961. doi:10.1038/s41390-020-0980-9

105. Sabih A, Russel C, Chang CL. Thunderstorm-related asthma can occur in New Zealand. Respirol Case Rep. 2020;8(7):1-3. doi:10.1002/rcr2.655
Journal of Inflammation Research

\section{Publish your work in this journal}

The Journal of Inflammation Research is an international, peerreviewed open-access journal that welcomes laboratory and clinical findings on the molecular basis, cell biology and pharmacology of inflammation including original research, reviews, symposium reports, hypothesis formation and commentaries on: acute/chronic inflammation; mediators of inflammation; cellular processes; molecular
Dovepress

mechanisms; pharmacology and novel anti-inflammatory drugs; clinical conditions involving inflammation. The manuscript management system is completely online and includes a very quick and fair peerreview system. Visit http://www.dovepress.com/testimonials.php to read real quotes from published authors. 